\title{
Genital ulcer disease in men in Durban, South Africa
}

\author{
N O'Farrell, A A Hoosen, K D Coetzee, J van den Ende
}

\begin{abstract}
Objective-To study the microbial aetiology of genital ulcer disease (GUD) in men.

Design-Microbiological and clinical assessment of genital ulcers in men.

Setting-City Health sexually transmitted diseases clinic, King Edward VIII Hospital, Durban, South Africa.

Participants-100 Zulu men with genital ulcers who had not received antibiotics in the previous four weeks.

Results-Syphilis was diagnosed in $42 \%$, chancroid in $22 \%$, donovanosis (granuloma inguinale) in $11 \%$, genital herpes in $10 \%$ and lymphogranuloma venereum (LGV) in $6 \%$. No pathogens were identified in $24 \%$. Mixed infections were detected in 14 men, in whom 13 had syphilis. Five men had HIV-1 antibodies. Neisseria gonorrhoeae was isolated from the ulcers and urethra in seven men and from the urethra alone in five. Scabies was diagnosed clinically in eight.

Conclusions-All the major causes of GUD are prevalent in Zulu men in Durban. Primary syphilis was the commonest and was invariably present in mixed infections. Donovanosis was under-reported and was associated with a long delay before presentation. In this population, genital ulcers other than superficial lesions should be treated with anti-syphilitic therapy and oral antibotics effective against chancroid and donovanosis.
\end{abstract}

\section{Introduction}

Genital ulcer disease (GUD) is a frequent problem amongst men attending the City Health sexually transmitted diseases (STD) clinic, King Edward VIII Hospital, Durban. Approximately 6000 men with GUD are seen per annum. In a microbiological study of men with GUD in Durban in 1984, ${ }^{1}$ syphilis and chancroid accounted for most cases and dono-

City Health STD Department, King Edward VIII Hospital, Durban

N O'Farrell

Department of Medical Microbiology, Faculty of Medicine, University of Natal, Durban, Sauth Africa A A Hoosen, K D Coetzee, J van den Ende vanosis (granuloma iguinale) was unreported. Following the introduction of a rapid staining technique for the detection of Donovan bodies in tissue smears, ${ }^{2}$ a clinical impression that donovanosis was prevalent locally was confirmed.

Human immunodeficiency virus (HIV) infection is associated with $\mathrm{GUD}^{3}$ but the relationship is complex and may be in part cause and part effect. A further independent risk factor for HIV infection is the uncircumcised state. ${ }^{4}$ Higher prevalences of HIV-1 are reported in uncircumcised tribal groups from diverse geographical locations in Africa. ${ }^{5}$ Genital ulceration with genital herpes ${ }^{6}$ and chancroid ${ }^{4}$ are both associated with HIV infection and are more common in uncircumcised men. ${ }^{78}$ Recently HIV infection has been identified amongst men attending this clinic. $^{9}$ The suspicion of changed disease prevalences in this population in whom circumcision is uncommon led us to re-investigate the microbial aetiology of GUD amongst men in Durban.

\section{Patients and methods}

One hundred black men attending the City Health STD Clinic at King Edward VIII Hospital, Durban with GUD who had not received antibiotics during the previous four weeks were entered into the study. Informed consent was obtained from all patients and the study was completed between August 1988 and January 1989. A detailed history was obtained with the help of a clinic health assistant, acting as interpreter. Genital examination was performed and the size, site and nature of ulceration, presence of lymphadenopathy and skin rashes was recorded.

\section{Microbiological investigations}

The microbiological methods used were identical to those in the study of women with GUD in this issue except that urethral specimens were examined for evidence of infection with Neisseria gonorrhoeae. ${ }^{10}$

\section{Results}

The mean age of the men was 25.6 (range 15-58) years. Seventy eight men were unmarried and 62 were new attenders to the clinic. Prior treatment, which did not include antibiotics had been obtained by 39 men; 28 from traditional healers (Inyangas), five from private doctors, four from friends and two from hospital doctors. Five men admitted contact with a prostitute as the likely source of infection. The 
duration of symptoms ranged from one day to six months (table 1), Thirty four men had had genital ulcers for longer than 14 days, by the date of presentation.

The mean number of ulcers was 2.8 (range one to nine). Thirty five men had one ulcer, 21 had two ulcers, $37 \mathrm{had}$ three to five ulcers and seven had six to

Table 1 Duration of symptoms before presentation in 100 men with genital ulceration

\begin{tabular}{ll}
\hline $\begin{array}{l}\text { Duration of symptoms } \\
\text { (days) }\end{array}$ & No (\%) of men \\
& $N=100$ \\
\hline $1-7$ & 35 \\
$8-14$ & 31 \\
$15-21$ & 7 \\
$22-30$ & 18 \\
$31-90$ & 7 \\
$91-180$ & 2 \\
\hline
\end{tabular}

Table 2 Pathogens isolated from genital ulcers, sexually transmitted diseases and other infections in 100 Zulu men

\begin{tabular}{lc}
\hline & No of Men (\%) \\
\hline Single infections & 29 \\
Syphilis & 12 \\
Chancroid & 9 \\
Donovanosis & 9 \\
Genital Herpes & 3 \\
LGV & \\
Double infections & 8 \\
Syphilis + Chancroid & 2 \\
Syphilis + LGV & 1 \\
Syphilis + Donovanosis & 1 \\
Syphilis + Genital Herpes & 1 \\
Chancroid + LGV & 1 \\
Triple infections & 24 \\
Syphilis + Chancroid + Donovanosis & \\
No pathogens detected & 8 \\
Additional diagnosis & 7 \\
Scabies & 7 \\
Balanitis & 5 \\
Gonorrhoea - ulcer + urethra & 5 \\
HIV-1 seropositive & 1 \\
Behcet's Diseases & \\
\hline
\end{tabular}

nine ulcers. The diameter of the largest ulcer ranged from three $\mathrm{mm}$ to $30 \mathrm{~mm}$. Most ulcers were situated either on the prepuce, coronal sulcus or penile shaft. The foreskin was intact in 98 men. Sixteen were unable to fully retract their foreskin due either to pain or phimosis. Difficulty in retraction was observed in a further seven men. Three men had frank bleeding whilst retracting the foreskin. Slight bleeding was observed in 26 men during swab collection. A purulent exudate around the edges of the foreskin was observed in 19. Inguinal lymphadenopathy was detected unilaterally in 25 men and bilaterally in 37 . Ten men had buboes, six requiring aspiration.

Syphilis was diagnosed in $\mathbf{4 2}$ men (table 2) by the criteria chosen. Primary chancres were observed in all cases. Ulcerated condylomata lata were present in one man. A further eight men had reactive RPR and TPHA tests. $T$ pallidum infection was diagnosed in 13 of 14 men with mixed infections, including eight with chancroid. Primary chancres were larger than ulcers of HSV or chancroid (table 3) and bled to the touch.

$H$ ducreyi was isolated from $22 \mathrm{men}$; as a single infection in 12 and a mixed infection in ten. Chancroid ulcers were slightly larger and fewer than those of $\mathrm{HSV}$ which were of smaller diameter. $\mathrm{HSV}$ was detected as a single infection in nine men and as a mixed infection in one.

Donovan bodies were detected in smears of nine men with single infections and two with mixed infections. Distinguishing features of donovanosis ulcers were: large diameters, fewer ulcers, bleeding to the touch and long delay before presentation. Lymphogranuloma venereum (LGV) was diagnosed in six men in whom ulcers tended to be small in size.

$N$ gonorrhoeae was isolated from the urethra and ulcers of seven men and from the urethra alone in five. Ninety five men consented to HIV antibody testing. Five were seropositive. Scabies was diagnosed clinically in eight.

Table 3 Features of genital ulcer disease in men

\begin{tabular}{|c|c|c|c|c|c|c|c|}
\hline \multirow[b]{2}{*}{ Feature } & \multicolumn{7}{|l|}{ Diagnosis } \\
\hline & $\begin{array}{l}\text { Syphilis } \\
N=29\end{array}$ & $\begin{array}{l}\text { Chancroid } \\
N=12\end{array}$ & $\begin{array}{l}\text { Donovanosis } \\
N=9\end{array}$ & $\begin{array}{l}\text { Genital Herpes } \\
N=9\end{array}$ & $\begin{array}{l}L G V \\
N=3\end{array}$ & $\begin{array}{l}\text { No Cause } \\
N=24\end{array}$ & $\begin{array}{l}\text { Mixed Infe } \\
N=14\end{array}$ \\
\hline $\begin{array}{l}\text { Mean no of ulcers } \\
\text { Range } \\
\text { Mean diameter of }\end{array}$ & $\begin{array}{c}2 \cdot 3 \\
(1-6)\end{array}$ & $\begin{array}{c}3 \cdot 3 \\
(1-7)\end{array}$ & $\begin{array}{c}1 \cdot 5 \\
(1-5)\end{array}$ & $\begin{array}{l}4 \cdot 3 \\
(1-10)\end{array}$ & $\begin{array}{c}1 \cdot 7 \\
(1-3)\end{array}$ & $\begin{array}{c}3 \cdot 3 \\
(1-6)\end{array}$ & $\begin{array}{c}2 \cdot 6 \\
(1-7)\end{array}$ \\
\hline $\begin{array}{l}\text { largest ulcer (mm) } \\
\text { Range } \\
\text { Mean delay before }\end{array}$ & $\begin{array}{l}11 \cdot 2 \\
(3-30)\end{array}$ & $\begin{array}{c}6 \cdot 4 \\
(5-10)\end{array}$ & $\begin{array}{l}12 \cdot 2 \\
(5-20)\end{array}$ & $\begin{array}{l}4 \cdot 5 \\
(3-30)\end{array}$ & $\begin{array}{l}6 \cdot 8 \\
(5-10)\end{array}$ & $\begin{array}{l}7 \cdot 8 \\
(3-10)\end{array}$ & $\begin{array}{c}7 \cdot 4 \\
(4-10)\end{array}$ \\
\hline $\begin{array}{l}\text { presentation (days) } \\
\text { Range } \\
\text { Bleeding from ulcer site }\end{array}$ & $\begin{array}{l}15 \cdot 9 \\
(3-120)\end{array}$ & $\begin{array}{l}11 \cdot 6 \\
(3-28)\end{array}$ & $\begin{array}{l}26 \cdot 6 \\
(3-180)\end{array}$ & $\begin{array}{l}8 \cdot 7 \\
(3-30)\end{array}$ & $\begin{array}{l}24 \cdot 6 \\
(14-35)\end{array}$ & $\begin{array}{l}11 \cdot 9 \\
(3-60)\end{array}$ & $\begin{array}{l}17 \cdot 8 \\
(9-35)\end{array}$ \\
\hline $\begin{array}{l}\text { during swab collection } \\
\text { Inguinal lymphadenopathy }\end{array}$ & 6 & 3 & 6 & 1 & - & 6 & 4 \\
\hline $\begin{array}{l}\text { Unilateral } N=25 \\
\text { Bilateral } N=37\end{array}$ & $\begin{array}{r}7 \\
15\end{array}$ & $\begin{array}{l}3 \\
1\end{array}$ & $\begin{array}{l}2 \\
1\end{array}$ & $\frac{-}{3}$ & $\begin{array}{l}2 \\
1\end{array}$ & $\begin{array}{l}4 \\
9\end{array}$ & $\begin{array}{l}7 \\
7\end{array}$ \\
\hline Bubo $N=10$ & 2 & 3 & - & - & 1 & 4 & - \\
\hline
\end{tabular}


No pathogens recognised as causing GUD were detected in 24 men. In this group TPHA and RPR tests were both positive in two men and $N$ gonorrhoeae was isolated from the ulcer and urethra of three. Behcet's disease was diagnosed in one man with scrotal ulceration, oral ulcers and anterior uveitis.

\section{Discussion}

Records of attendances at STD clinics in South Africa are published in the annual reports of the medical officers of health of local authorities and municipalities. In Durban the numbers of male attenders with GUD have remained consistently high over the past ten years. In this study we found that all the major causes of GUD were prevalent in Durban. Syphilis was the most frequent cause and was diagnosed in $42 \%$ follaw wed by chancroid in $22 \%$, donovanosis in $11 \%$, genital herpes in $10 \%$ and LGV in $6 \%$. Previous studies have detected high prevalences of syphilis of $44 \%$ in Durban ${ }^{1}$ and $33 \%$ in Pretoria ${ }^{11}$ but elsewhere in Africa, in Nairobi, ${ }^{12}$ the Gambia ${ }^{13}$ and Johannesburg, South Africa, ${ }^{14}$ chancroid is more common. Many patients referred to this clinic are seen following treatment elsewhere with either benzathine or procaine penicillin given for syphilis by multiple injections in sub-therapeutic doses. Parenteral therapy is a popular form of treatment requested by men in this clinic and dissatisfaction is not uncommon if tablets are offered rather than the expected injection, which traditionally is regarded as the stronger medicine.

In our study features suggestive of primary syphilis were: fewer ulcers, large diameter and tendency to bleed during swab collection. The presence of either unilateral or bilateral lymphadenopathy was of limited value in making a correct clinical diagnosis.

Although donovanosis was not diagnosed in a previous local study performed in $1984,{ }^{1}$ the prevalence of $11 \%$ in this study was not unexpected following the introduction into routine use of a rapid diagnostic test for the detection of Donovan bodies in ulcer smears. Donovanosis has been recognised in South Africa at least since $1916^{15}$ but little mention is made in the medical literature until the 1980s. Whether this re-emergence is a genuine phenomenon or a result of changed awareness and improved clinical recognition, is uncertain. Variable nomenclature and confusion with lymphogranuloma venereum (LGV) in the absence of confirmatory diagnostic techniques has probably accounted for many cases of misdiagnosis. Lymphogranuloma iguinale and granuloma venereum are terms still used synonymously for these conditions by some authorities. Elsewhere in Southern Africa donovanosis is described in $\mathrm{Zambia}^{16}$ and Zimbabwe ${ }^{17}$ but our data suggest a much higher prevalence in Durban. Ulcers of donovanosis tended to be large, few in number, bleed during swab collection and associated with a long delay before presentation.

In 1984 the prevalence of chancroid in Durban was $40 \%$ compared with $22 \%$ in our study. Variation in batches of culture media in which a higher concentration of vancomycin $(5 \mathrm{mg} / \mathrm{l})$ was used may have inhibited growth of the organism. Chancroid infections are more prevalent amongst prostitutes and their contacts but in our study five men only admitted paying a source contact. This lower prevalence of chancroid is unlikely to reflect reduced prostitute contact following the national AIDS awareness campaign as knowledge and awareness of AIDS amongst local men is poor. ${ }^{18}$

The distinction between the various causes of small ulcers was difficult. Features suggestive of chancroid rather than herpes genitalis were: larger diameter and fewer ulcers. In Nairobi, chancroid is a risk factor for HIV infection ${ }^{4}$ but locally HSV carries a greater risk. ${ }^{19}$ In the absence of effective cheap antiviral therapy, antimicrobial treatment for chancroid may be justified in all patients with small ulcers and an indeterminate aetiological diagnosis. LGV was diagnosed in $6 \%$ in this study which is greater than $1 \%$ in Durban in 1984, but less than $13 \%$ in nearby Swaziland ${ }^{20}$ or $17 \%$ in Carltonville, South Africa. ${ }^{21}$ Possible contamination of ulcers with secretions from chlamydial urethritis was unlikely given that none of those diagnosed with LGV had evidence of urethral discharge. Other more accurate methods for the detection of $C$ trachomatis infection, that is, by culture and serology (micro-immunofluorescence) were unavailable to us and the true prevalence of LGV was probably underestimated in this study.

Ulcers from which no recognised pathogens were detected tended to be small. Sixteen of 24 were diagnosed clinically as chancroid or genital herpes. A failure to detect these organisms in significant numbers of patients in endemic areas is not unusual. Donovanosis was the likely diagnosis in three men and biopsy with histological examination may be required for the detection of Donovan bodies in early or small lesions. Practical difficulties in obtaining specimens in the confines of a busy clinic precluded this procedure in our study. $N$ gonorrhoeae was isolated from the ulcers and urethra of three men in this group, all with chancroid as the first choice clinical diagnosis, making self contamination likely.

Clinical signs were unhelpful in distinguishing between single and mixed infections. Syphilis was present in 13 of 14 mixed infections, thereby justifying empirical anti-syphilitic treatment for ulcers with atypical appearances. Benzathine penicillin remains the only effective single dose therapy for syphilis and is particularly suitable for use in under-developed countries where compliance with daily injections of procaine penicillin is likely to be poor. However, any management protocol for use in Africa must now take 
into account the interaction between HIV and GUD. Reports doubting the efficacy of benzathine penicillin in the treatment of syphilis in HIV seropositives ${ }^{22}$ are worrying, given the high prevalence of both infections in the community. Chancroid heals more slowly in HIV-1 seropositives ${ }^{23}$ and the response to treatment in donovanosis may be similar. Our findings support the use of oral antibiotics for genital ulcers other than superficial lesions. Co-trimoxazole is a cheap and effective treatment for most cases of chancroid and donovanosis locally but is associated with an increased prevalence of adverse reactions in HIV-1 seropositive patients and its future use must be monitored closely. Erythromycin is also effective against local strains of $H$ ducreyi but the response in donovanosis is variable and prolonged treatment may be required.

Traditional healers were consulted by 28 men, who were treated with diuretics, purgatives, enemas and local herb applications, sometimes at considerable expense. Some patients appeared to believe that their ulcers were derived from a curse or evil spirit and reflect a need for improved health education.

HIV-1 antibodies were detected in five men. Black male heterosexual attenders at STD clinics in South Africa have been identified as being at increased risk of $\mathrm{HIV}^{9}$ and GUD is a risk factor in Durban. ${ }^{19}$ The heterosexual HIV epidemic in South Africa has evolved southward from Central and Eastern Africa and circumcision in certain male tribal groups may have protected against the rapid spread of HIV infection in northern areas of South Africa where the prevalence of HIV-1 seropositivity is less than in Natal where circumcision is uncommon amongst Zulus. Circumcision could be promoted and perhaps performed by traditional healers who have not so far assumed a significant role in addressing the HIV problem.

The control of STD and GUD in the local population, many of whom live in squatter camps with poor sanitation, presents a major challenge to public health authorities. Liaison between doctors, epidemiologists, social scientists, laboratory workers, inyangas and indunas (tribal headmen) could dispel many of the myths that have grown around STDs and AIDS in this community and thereby contribute towards decreasing the prevalence of GUD and limiting the spread of HIV.

We thank the staff at the City Health STD Clinic, including all doctors, sisters and Health assistants, especially Bernard Zulu, for their co-operation.
Address for correspondence: Dr Nigel O'Farrell, Lydia Department, St Thomas' Hospital, London SE1 7RH, UK.

1 Coovadia YM, Kharsany AB, Hoosen AA. The Microbial Aetiology of Genital Ulcers in Black Men in Durban, South Africa. Genitourin Med 1985;61:266-9.

2 O'Farrell N, Hoosen AA, Coetzee K, van den Ende J. A rapid stain for the diagnosis of granuloma inguinale (donovanosis). Genitourin Med 1990;66:200-1.

3 Piot P, Laga M. Genital Ulcers, Other Sexually Transmitted Diseases and the Sexual Transmission of HIV. BMJ 1989; 298:623-34.

4 Cameron DW, Simonsen JN, D'Costa LJ et al. Female to Male transmission of human immunodeficiency virus type 1: risk factors for seroconversion in men. Lancet 1989;ii:404-7.

5 Bongaarts J, Reining P, Way P, Conant F. The relationship between male circumcision and HIV Infection in African Populations. AIDS 1989;3:373-7.

6 Stamm WE, Handsfield HH, Rompalo AM, Ashley RL, Roberts PL, Corey $\mathrm{L}$. The association between genital ulcer disease and acquisition of HIV infection in homosexual men. $J A M A$ 1988;260:1429-33.

7 Taylor PK, Rudin P. Herpes genitalis and circumcision. $\mathrm{Br} \mathrm{J}$ Venereal Dis 1975;51:274-7.

8 Hart G. Factors influencing venereal infection in a war environment. Br J Venereal Dis 1974;50:68-72.

9 O'Farrell N, Windsor I. Prevalence of HIV antibody in recurrent attenders at a sexually transmitted disease clinic. $S$ Afr Med J 1988;74:104-5.

10 O'Farrell N, Hoosen AA, Coetzee KD, van den Ende J. Genital ulcer disease in women in Durban, South Africa. Genitourin Med 1991;67:322-6.

11 Crewe-Brown HH, Krige FK, Davel GH et al. Genital ulceration in males at Ga-Rankuwa Hospital, Pretoria. $S$ Afr Med J 1982;62:861-3.

12 Nsanze H, Fast MV, D'Costa LJ, Tukei P, Curran J, Ronald A. Genital ulcers in Kenya. A clinical and laboratory study. $\mathrm{Br} J$ Venereal Dis 1981;57:378-81.

13 Mabey DC, Wall RA, Bello CS. Aetiology of genital ulceration in the Gambia. Genitourin Med 1987;63:312-5.

14 Duncan MO, Bilgeri YR, Fehler HG, Ballard RC. The diagnosis of sexually acquired genital ulcerations in black patients in Johannesburg. Southern African Journal of Sexually Transmitted Diseases 1981;1:20-23.

15 Ricono M. Yaws and similar diseases in South Africa. South African Medical Record 1916;14:83-9.

16 Bhagwandeen SB, Naik KG. Granuloma Venereum (Granuloma inguinale) in Zambia. East Afr Med J 1977;54: 637-42.

17 Latif AA, Mason PR, Paraiwa E. The treatment of donovanosis (granuloma inguinale). Sex Transm Dis 1988;15:27-9.

18 O'Farrell N, Will R. Sexual Behaviour, knowledge, attitudes and awareness of AIDS amongst sexually transmitted disease clinic attenders in Durban following the national campaign. Southern African Journal of Epidemiology and Infection 1989; 4:45-48.

19 O'Farrell N, Windsor I, Becker P. Risk Factors for HIV-1 amongst STD Clinic Attenders in Durban, South Africa. Sixth International Conference on AIDS, San Francisco, June 1990. (Abstract F.C. 604)

20 Meheus A, Van Dyck E, Ursi JP, Ballard RC, Piot P. Etiology of genital ulceration in Swaziland. Sex Transm Dis 1983;10: 33-35.

21 Dangor Y, Fehler G, Exposto F, Koornhoff HJ. Causes and treatment of sexually acquired genital ulceration in Southern Africa. $S$ Afr Med J 1989;76:339-41.

22 Hook EW. Syphilis and HIV Infection. J Infect Dis 1989; 160:530-4.

23 Cameron DW, Plummer FA, D'Costa LJ, Ndinya-Achola JO, Ronald AR. Prediction of HIV Infection by treatment failure for chancroid, a genital ulcer disease. Fourth International Conference on AIDS, Stockholm, June 1988.

Accepted for publication 17 April 1991 